\title{
Tumor Suppressor Gene ARID1A in Cancer: Recent Advances and Future Perspective
}

\author{
Nottegar $\mathbf{A}^{1}$, Veronese $\mathbf{N}^{2}$, Solmi $\mathbf{M}^{3}$ and Luchini $\mathbf{C}^{1,4^{*}}$ \\ ${ }^{1}$ Department of Pathology and Public Health, University and Hospital Trust of Verona, Verona, Italy \\ ${ }^{2}$ Department of Medicine (DIMED), University of Padua, Padua, Italy \\ ${ }^{3}$ Department of Neuroscineces, University of Padua, Padua, Italy \\ ${ }^{4}$ Surgical Pathology Unit, Santa Chiara Hospital, Trento, Italy
}

*Corresponding author: Luchini C, Department of Pathology and Public Health University and Hospital Trust of Verona, Piazzale LA Scuro, 1037134 Verona (VR), Italy, Tel: 00390458124842, Fax: 00390458127136, E-mail: claudio.luchini@katamail.com

Received date: January 20, 2016; Accepted date: February 25, 2016; Published date: February 29, 2016

Copyright: @ 2015, Nottegar A, et al. This is an open-access article distributed under the terms of the Creative Commons Attribution License, which permits unrestricted use, distribution, and reproduction in any medium, provided the original author and source are credited.

Keywords: Tumor suppressor gene; ARID1A; Human malignancies; Prognostic genes

\section{Introduction}

Tumor suppressor gene AT-rich interactive domain 1A (ARID1A) is a subunit of the Switch/Sucrose Non-Fermentable (SWI/SNF) chromatin-remodeling complex; it regulates gene expression by controlling gene accessibility [1,2]. Genes involved in epigenetic mechanisms establishing chromatin structure are very often mutated in different cancer types; among these, gynecological and gastrointestinal malignancies play a very important role [3-9]. Particularly, ARID1A shows one of the highest mutation rates among human malignancies [10]. Therefore, there is considerable interest in developing cancer therapeutics that can negatively interact with ARID1A mutational status. A recent report showed a synthetic lethality by targeting EZH2 (enhancer of zeste 2 polycomb repressive complex 2 subunit) histone methyltransferase activity in ARID1Amutated clear cell ovarian cancer, thanks to a small-molecule inhibitor, available and clinically applicable [11]. Its synthetic lethality is associated with inhibition of PI3K (phosphatidylinositol-4,5bisphosphate 3-kinase catalytic subunit alpha) / AKT (v-akt murine thymoma viral oncogene homolog 1) signaling. Furthermore, there is evidence suggesting that ARID1A-mutated cancer may also be treated by targeting residual SWI/SNF activity, the PI3K/AKT pathway, the tumor immunological microenvironment, stabilizing wild-type p53 and by targeting the DNA damage response $[10,12]$. About the DNA damage response, a recently developed class of drugs, the poly(ADPribose) polymerase-inhibitors (PARPi), are currently being developed in clinical trials as a targeted treatment, acting on the pathway of DNA repair [13]. PARP-1 is a well-characterized protein in the PARP family: through the base excision repair pathway, it is critical to the repair of single-strand DNA breaks [13-15]. The inhibition of PARP conducts to the accumulation of single-strand breaks, resulting in double-strand breaks. In cells with defective HR (homologous recombination) gene, like the BRCA(Breast Cancer gene)-mutations carriers, PARP inhibition can lead to chromosomal instability, cell cycle arrest and subsequent apoptosis [14]. Recently, similarly to BRCA, also ARID1A mutations have been associated with defects in DNA repair, indicating tumors with such mutations as another possible target of PARPi [15]. Since ARID1A mutations are prognostic significant [12,16-19], further studies and clinical trials are needed to define the possible effects of PARPi on ovarian tumors, not only with BRCA1 (Breast Cancer 1) and BRCA2 (Breast Cancer 2) genes, but also with ARID1A mutations.

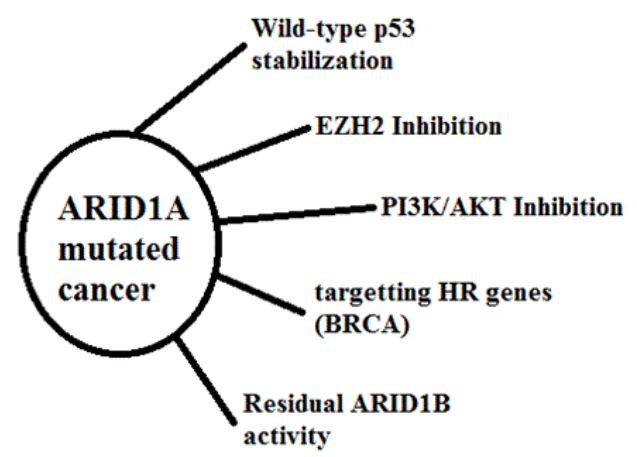

Figure 1: The incomplete "sun" of ARID1A-mutated cancers. Some rays of this "sun", as shown in this figure, have already been discovered, but we need to further investigate ARID1A-mutated cancer to understand the role of many other rays. Tumor immunological microenvironment does not represent an actual ray for now, but it will be the first one to be added, obviously after further investigations.

Noticeably, a recent meta-analysis indicate that loss of ARID1A shortened time to cancer-specific mortality as well as to recurrence of disease, when adjusting for potential confounders, highlighting the importance of the the search of new therapeutic strategies against tumors with its mutation. A very important aim for surgical pathologist and oncologist, towards personalized medicine, is to investigate and to document on the final pathology report all the morphological aspects with a prognostic impact (e.g.: presence of nodal metastasis, extra-nodal extension of nodal metastasis, presence of vascular embolization) [20-24] and all the molecular features (e.g. BRCA mutations, ARID1A mutations) [12,25] that can indicate the prognosis and may address the therapies. To this aim, the most important prognostic genes, as ARID1A, have to be studied in depth.

\section{References}

1. Wu JN, Roberts CW (2013) ARID1A mutations in cancer: another epigenetic tumor suppressor? Cancer Discov 3: 35-43.

2. Flores-Alcantar A, Gonzalez-Sandoval A, Escalante-Alcalde D, Lomelí H (2011) Dynamics of expression of ARID1A and ARID1B subunits in 
mouse embryos and in cells during the cell cycle. Cell Tissue Res 345: 137-148.

3. Wu RC, Wang TL, Shih IeM (2014) The emerging roles of ARID1A in tumor suppression. Cancer Biol Ther 15: 655-664.

4. Nie Z, Xue Y, Yang D, Zhou S, Deroo BJ, et al. (2000) A specificity and targeting subunit of a human SWI/SNF family-related chromatinremodeling complex. Mol Cell Biol 20: 8879-8888.

5. Samartzis EP, Noske A, Dedes KJ, Fink D, Imesch P (2013) ARID1A mutations and PI3K/AKT pathway alterations in endometriosis and endometriosis-associated ovarian carcinomas. Int J Mol Sci 14: 18824-18849.

6. Mao TL, Shih IeM (2013) The roles of ARID1A in gynecologic cancer. J Gynecol Oncol 24: 376-381.

7. Simbolo M, Fassan M, Ruzzenente A, Mafficini A, Wood LD, et al. (2014) Multigene mutational profiling of cholangiocarcinomas identifies actionable molecular subgroups. Oncotarget 5: 2839-2852.

8. Jiao Y, Pawlik TM, Anders RA, Selaru FM, Streppel MM, et al. (2013) Exome sequencing identifies frequent inactivating mutations in BAP1, ARID1A and PBRM1 in intrahepatic cholangiocarcinomas. Nat Genet 45: 1470-1473.

9. Ruzzenente A, Fassan M, Conci S, Simbolo M, et al. (2015) Cholangiocarcinoma Heterogeneity Revealed by Multigene Mutational Profiling: Clinical and Prognostic Relevance in Surgically Resected Patients. Ann Surg Oncol .

10. Bitler BG, Fatkhutdinov N, Zhang R (2015) Potential therapeutic targets in ARID1A-mutated cancers. Expert Opin Ther Targets 19: 1419-1422.

11. Bitler BG, Aird KM, Garipov A, Li H, Amatangelo M, et al. (2015) Synthetic lethality by targeting EZH2 methyltransferase activity in ARID1A-mutated cancers. Nat Med 21: 231-238.

12. Luchini C, Veronese N, Solmi M, Cho H, et al. (2015) Prognostic role and implications of mutation status of tumor suppressor gene ARID1A in cancer: a systematic review and meta-analysis. Oncotarget 6: 39088-39097.

13. Mafficini A, Simbolo M, Parisi A, Rusev B, et al. (2016) BRCA somatic and germline mutation detection in paraffin embedded ovarian cancers by next-generation sequencing. Oncotarget 7: 1076-1083.

14. Wagner LM (2015) Profile of veliparib and its potential in the treatment of solid tumors. Onco Targets Ther 8: 1931-1939.

15. Shen J, Peng Y, Wei L, Zhang W, Yang L, et al. (2015) ARID1A Deficiency Impairs the DNA Damage Checkpoint and Sensitizes Cells to PARP Inhibitors. Cancer Discov 5: 752-767.
16. Katagiri A, Nakayama K, Rahman MT, Rahman M, Katagiri H, et al. (2012) Loss of ARID1A expression is related to shorter progression-free survival and chemoresistance in ovarian clear cell carcinoma. Mod Pathol 25: $282-288$.

17. Lowery WJ, Schildkraut JM, Akushevich L, Bentley R, Marks JR, et al. (2012) Loss of ARID1A-associated protein expression is a frequent event in clear cell and endometrioid ovarian cancers. Int J Gynecol Cancer 22: 9-14.

18. Yamamoto S, Tsuda H, Takano M, Tamai S, Matsubara O (2012) Loss of ARID1A protein expression occurs as an early event in ovarian clear-cell carcinoma development and frequently coexists with PIK3CA mutations. Mod Pathol 25: 615-624.

19. Maeda D, Mao TL, Fukayama M, Nakagawa S, Yano T, et al. (2010) Clinicopathological significance of loss of ARID1A immunoreactivity in ovarian clear cell carcinoma. Int J Mol Sci 11: 5120-5128.

20. Luchini C, Veronese N, Pea A, Sergi G, Manzato E, et al. (2016) Extranodal extension in N1-adenocarcinoma of the pancreas and papilla of Vater: a systematic review and meta-analysis of its prognostic significance. Eur J Gastroenterol Hepatol 28: 205-209.

21. Veronese N, Nottegar A, Pea A, Solmi M, Stubbs B, et al. (2016) Prognostic impact and implications of extracapsular lymph node involvement in colorectal cancer: a systematic review with meta-analysis. Ann Oncol 27: 42-48.

22. Veronese N, Luchini C, Nottegar A, Kaneko T, Sergi G, et al. (2015) Prognostic impact of extra-nodal extension in thyroid cancer: A metaanalysis. J Surg Oncol 112: 828-833.

23. Luchini C, Nottegar A, Solmi M, Sergi G, Manzato E, et al. (2015) Prognostic implications of extranodal extension in node-positive squamous cell carcinoma of the vulva: A systematic review and metaanalysis. Surg Oncol .

24. Luchini C, Nottegar A, Pea A, Solmi M, Stubbs B, et al. (2016) Extranodal extension is an important prognostic parameter for both colonic and rectal cancer. Ann Oncol

25. Luchini C, Capelli P, Fassan M, Simbolo M, Mafficini A, et al. (2014) Next-generation histopathologic diagnosis: a lesson from a hepatic carcinosarcoma. J Clin Oncol 32: e63-66. 